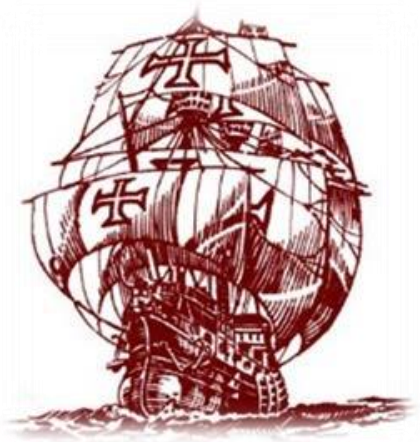

\author{
Nau Literária: crítica e teoria de literaturas \\ www.seer.ufrgs.br/nauliteraria \\ ISSN 1981-4526 - PPG-LET-UFRGS - Porto Alegre \\ Vol. 11 N. 02 \\ Literatura e Guerra
}

\title{
AS VARIANTES BÉLICAS EM A GUERRA NO BOM FIM, DE MOACYR SCLIAR
}

\author{
SHEILA KATIANE STAUDT ${ }^{\mathrm{i}}$
}

Resumo: O primeiro romance de Moacyr Scliar, A guerra no Bom Fim, publicado em 1972, é tecido pela rememoração de um menino judeu que narra preciosos momentos de sua infância no bairro Bom Fim, na mesma época em que eclode a Segunda Guerra Mundial na Europa. O imaginário do protagonista Joel está repleto de acontecimentos relacionados à guerra que permeiam suas lembranças e fazem parte de sua narração, mesclando realidade e fantasia em seu texto. Esse universo bélico mágico criado pelo garoto tem origem, principalmente, nas notícias que escutava sobre o que se passava em solo europeu a partir das conversas entre os adultos, dos meios de comunicação do período, bem como das idas ao cinema Baltimore, onde os cartazes dos filmes atraiam os jovens nas matinês de domingo. Fredric Jameson, em seu texto War and Representation, percebe oito variantes nos textos que tematizam a guerra, são elas: a) experiência existencial da guerra; b) experiência coletiva da guerra; c) líderes, oficiais e o exército; d) tecnologia; e) paisagem inimiga; f) atrocidades; g) ataque à pátria e h) ocupação estrangeira. Com isso em mente, tentaremos desvelar as variantes bélicas propostas por Jameson no texto de Scliar, a fim de compreender a experiência existencial pela qual passou a personagem que, para se defender das brutalidades do mundo real, passa a criar um cenário fantástico-maravilhoso em que a história e as lendas judaicas ganham vida, enfatizando a via crucis de toda uma geração de imigrantes que chega ao Brasil e sofre com o desenraizamento, preconceito e condições precárias de vida.

Palavras-chave: Variantes bélicas. Guerra. Representação. Literatura.

Abstract: Moacyr Scliar's first novel, A guerra no Bom Fim, published in 1972, is woven by the reminiscence of a Jewish boy who recounts precious moments of his childhood in the Bom Fim neighborhood at the time of II World War in Europe. The imaginary of the protagonist Joel is full of events related to the war itself that permeate his memories and are part of his narration, mixing reality and fantasy in his text. This magical warlike universe created by him has its origins mainly in the news he heard about what was happening on European soil from the conversations between the adults, the media of the period, and the trips to the Baltimore cinema, where the posters of the films attract young people on Sunday matinees. Fredric Jameson, in his text War and Representation, remarks eight variants or categories in the narratives that have the war as the main theme, they are: a) the existential experience of war; b) the collective experience of war; c) leaders, officers, and the institution of the army; d) technology; e) the enemy landscape; f) atrocities; g) attack on the homeland, and h) foreign occupation. With this in mind, we will try to unveil the warlike variants proposed by Jameson in the text of Scliar, in order to understand the existential experience through which the character passed, whose defense against the brutalities of the real world was to create a fantastic-wonderful scenario in that Jewish history and legends 
come to life, emphasizing the via crucis of a whole generation of immigrants that arrives in Brazil and suffers from rootlessness, prejudice and precarious conditions of life.

Keywords: Warfare variants. War. Representation. Literature.

Misto de fantasia e realismo, o primeiro romance de Moacyr Scliar é tecido pela rememoração de um menino que narra preciosos momentos de sua infância no bairro Bom Fim, de Porto Alegre, na época em que eclode a Segunda Guerra Mundial na Europa. O imaginário do menino Joel está repleto de acontecimentos relacionados à guerra que permeiam suas lembranças e fazem parte de sua narração, a qual se debruça em um "rico manancial de cantigas de ninar, contos fantásticos, lendas, estórias, anedotas e máximas da literatura ídiche antiga" (SZKLO, 1990, p. 22).

Aquele universo bélico mágico originava-se das notícias escutadas pelo protagonista sobre o que se passava na Europa por meio de conversas dos adultos ou pelos meios de comunicação do período. Decorriam também de sua frequência ao cinema Baltimore, cujos cartazes dos filmes atraíam os jovens nas matinês de domingo, e o que assistiam "sempre era de guerra e sempre era bom" (SCLIAR, 1981, p. 16).

De acordo com Fredric Jameson, em seu artigo War and Representation, de 2009,

there exists some stereotype of war [...] one often has the feeling that all war novels (and war films) are pretty much the same and have few enough surprises for us, even though their situations may vary. In practice, we can enumerate seven or eight situations, which more or less exhaust the genre. (JAMESON, 2009, p. 1533) ${ }^{1}$

Para o pesquisador, há oito variantes nos textos que têm a guerra como tema. São elas: a) experiência existencial da guerra; b) experiência coletiva da guerra; c) líderes, oficiais e o exército; d) tecnologia; e) paisagem inimiga; f) atrocidades; g) ataque à pátria e h) ocupação estrangeira.

A fim de identificar as variantes da guerra propostas por Fredric Jameson no romance de Scliar, embarcaremos naquele universo plural criado pelo menino para descrever sua infância fortemente atrelada aos noticiários bélicos. A maneira como o autor desenvolve a trama não deixa brechas para separar o fantástico do que realmente aconteceu naquela época, mérito do escritor, que propicia um mergulho completo na narrativa. Trabalharemos com a segunda versão deste romance publicada com o aval do autor em 1981.

Situando-nos no ano de 1943, o capítulo primeiro inicia com a descrição do Bom Fim enquanto um país, com suas fronteiras bem demarcadas e as dificuldades enfrentadas pela população em tempos de guerra: "poucos automóveis trafegavam pelas ruas do Bom Fim, quase todos a gasogênio: estava-se em guerra, a gasolina era escassa" (SCLIAR, 1981, p. 6). Percebemos que "o Bom Fim é a terra da fantasia, das atribulações da caça aos judeus pelos goim (gentios), da guerra contra os nazistas, dos ataques e das sucessivas vitórias. É o país dos sonhos para Joel” (SZKLO, 1990, p. 32), e serve de arena para os confrontos com

\footnotetext{
${ }^{1}$ Existem alguns estereótipos de guerra [...] um dos mais frequentes é a sensação que se tem de que os romances de guerra (e filmes de guerra) são praticamente iguais e trazem poucas surpresas para nós, mesmo que as suas situações variem. Na prática, nós podemos enumerar sete ou oito situações, as quais mais ou menos esgotam o gênero (JAMESON, 2009, p.1533, tradução nossa)
} 
o inimigo: "os nazistas estavam em toda parte; na Rua Fernandes Vieira foram descobertos numa fábrica de caramelos, que foi cercada e incendiada pelas tropas da Fernandes Vieira, grande quantidade de balas café com leite sendo capturada na ocasião" (SCLIAR, 1981, p. 9). Este cenário abriga a comunidade judaica em Porto Alegre e sofre alterações em sua fisionomia com a modernização, contudo, a memória coletiva dos imigrantes judeus perdura no novo traçado urbano: "construíram edifícios, dezenas de edifícios pelo Bom Fim, prédios de oito apartamentos distribuídos em quatro pisos, com fachada de granitina rosa ou amarela, e nomes de mães judias: Edifício Iente, Edifício Chava" (SCLIAR, 1981, p. 100).

A objetividade da linguagem empregada na apresentação dos fatos relacionados à guerra, propriamente dita, lembra manchetes de jornais e traz veracidade aos acontecimentos narrados, uma vez que o texto jornalístico prima pela imparcialidade e apuração da verdade sobre o que foi noticiado. Um dos recursos narrativos percebidos neste romance são as "frases de efeito", objetivas, como que retiradas das capas de jornais alertando o leitor sobre o que estaria acontecendo na Europa e consequentemente chamando a atenção para os reflexos no Bom Fim:

Batidos em Stalingrado e na Sicília, com problemas de abastecimento e ameaçados na África, os alemães se voltaram para o Bom Fim.

Este pequeno país estava de pé e mobilizado, sob as ordens do Rei Joel. Um ataque frontal não seria possível. A quinta-coluna entrou em ação.

Aconteceu na Festa do Divino.. (SCLIAR, 1981, p. 25)

Uma das variantes propostas por Fredric Jameson se refere aos líderes, oficiais e exército. No trecho citado, conhecemos o líder Joel, denominado Rei e, anteriormente, ficamos sabendo detalhes do grupo que o apoiava e as incumbências de cada um naquele exército protetor do Bom Fim:

No Bom Fim, Joel sentia-se como um Rei. Sentava-se displicentemente em seu trono, à sombra do cinamomo, rodeados de ministros: o das finanças, de olhinho esperto e riso matreiro; o da guerra, de olhar torvo; o chefe do serviço secreto, com o qual Joel conferenciava em voz baixa. Em volta, às cabriolas, movia-se a corte: dois gêmeos, um coxo, vários cachorros, um gato, um futuro deputado, muitos colorados. Mais ao longe, donzelas de risinho nervoso. Era Joel que elas admiravam, Rei e Capitão, terror dos nazistas. (SCLIAR, 1981, p. 20)

Colegas, amigos e até mesmo animais de estimação compunham o exército liderado por Joel e temido pelos nazistas. Ao mesmo tempo em que tinha o respeito de todos, o líder estava atento aos possíveis traidores do grupo, punindo-os sempre que necessário:

Rafael, encarregado da produção de estilingues, fê-los de borracha podre, pondo em risco a segurança de toda a turma.

Quando Joel soube, foi à casa dele para puni-lo. Escondido atrás de um armário, Rafael ouvia os gritos de Joel e sentia as fezes líquidas e quentes a lhe correrem pela perna. (SCLIAR, 1981, p. 42)

Joel era querido pelos seguidores, entretanto não hesitava em perseguir àqueles que colocavam seu exército em perigo, afinal, estava-se em guerra e qualquer deslize poderia significar a derrota do seu país. Neste exemplo, notamos uma das tecnologias empregadas 
pelos meninos do Bom Fim para defender seu território: os estilingues. Esta variante está presente no romance, e muitos outros artefatos bélicos são utilizados nos confrontos contra os nazistas:

$\mathrm{O}$ ataque veio de surpresa.

Quando a turma viu, os tanques vinham subindo a Rua Fernandes Vieira. Atrás avançavam as colunas de infantes, com lança-chamas. Carros blindados, armados com metralhadoras pesadas fechavam a retaguarda. E sobre os telhados roncavam Stukas e Messerschmitts! O Joel organizou rapidamente a defesa. Com garrafas de Charrua, gasolina e trapos prepararam "coquetéis Molotov" e atacaram os tanques no cruzamento da Fernandes Vieira com a Henrique Dias. [...] Armaram-se com fundas e paus. Da fábrica de móveis do Benjamim trouxeram o serrote, o formão, a torquês, a goiva, a pua; e uma arma secreta: um furador elétrico capaz de abrir um rombo nos peitos de qualquer nazi. (SCLIAR, 1981, p. 53-54)

A diferença entre a tecnologia inimiga e a dos meninos do Bom Fim fica evidente. Contudo, a vitória sempre é dos aliados de Joel que organizou e planejou bem o contraataque no coração do Bom Fim. Os meios de comunicação do período informavam que a "serpente nazista [...] não era imortal. Ela podia ser vencida. Gibi Mensal, Globo Juvenil, Cinema Baltimore, Cinema Rio Branco provavam isso constantemente" (SCLIAR, 1981, p. 27). Era essa, pois, a certeza advinda de fontes tão confiáveis, que permitiam ao grupo munir-se das armas de fácil alcance e que faziam parte do cotidiano infantil dos meninos.

Outras tecnologias também são empregadas nos demais confrontos com os nazistas. No verão, as famílias do Bom Fim iam para o litoral, principalmente esposas e os filhos. Em 1944, os nazistas descobrem esse costume e atacam a praia de Capão da Canoa:

Joel viu que a hora tinha chegado. Deu o sinal. Correram e se espalharam pelos cômoros de areia em frente ao Hotel Bassani, cada um com sua arma: Beto com um lançachamas, Jean com a soqueira-punhal, Dudi com o canivete de três lâminas, Francisco Zukerkorn com fuzil e baioneta, Motl Liberman, Pedro e Arnaldo com a bazuca. O Capitão Joel, ele mesmo, tinha uma metralhadora e doze granadas. (SCLIAR, 1981, p. 80)

Neste ponto, percebemos um considerável upgrade na tecnologia de Joel e seu grupo, se comparado às primeiras batalhas no Bom Fim. Por outro lado, os alemães não vieram desprevenidos, pois "tinham muita munição [...] e disparavam sem cessar. As balas zuniam no ar, os Stukas e Messerschmitts roncavam sobre Capão da Canoa. Atingida por um morteiro, a casinha do salva-vidas incendiou-se" (SCLIAR, 1981, p. 80-81).

Nestes episódios, há a presença de uma outra variante comum nos textos sobre a temática da guerra - o ataque à pátria. Apesar de Joel e seu grupo não estar mais no Bom Fim, mas em férias com a família na praia, os inimigos não dão trégua e resolvem atacar a pátria adjacente, pois "falava-se num plano nazista de dominar Capão da Canoa e de lá invadir o Bom Fim através de um túnel secreto que, partindo dos fundos do Hotel Bassani, avançava dezenas de quilômetros, terminando em certo bueiro da Rua Henrique Dias" (SCLIAR, 1981, p. 78). O objetivo primeiro dos adversários nazistas era a dominação do Bom Fim, mas o plano de chegar até lá via litoral, com a conquista de Capão da Canoa, torna-se um estratagema elaborado que, apesar de surpreender, num primeiro momento, o Capitão Joel e sua turma, foi passível de aniquilação. 
A derrocada do inimigo em Capão da Canoa só foi possível pelo aumento de ajuda recebida por Joel e seu grupo naquele território visitado apenas uma vez ao ano. Seu exército aumentou o número de aliados, exímios conhecedores daquelas areias e paragens, e experientes em combates, já que o intuito daqueles meninos ali era a fuga do calor excessivo que fazia no Bom Fim no verão, além de aproveitar bem o tempo de férias escolares, sem cogitar um ataque em tempos de diversão e descanso:

Não lutariam sós, assegurava [Joel]. Tinham ali aliados poderosos.

Lá estavam, escondidos entre os cômoros: o Príncipe Submarino, o Homem de Borracha e o Sombra; Sansão e Josué; o Golem. [...]

Ali estavam também os famosos boxadores judeus: Daniel Mendonza [...]; Samuel Elias, o "Dutch Sam", Issac Bittoon, Abraham Belasco e Barney Aron, "The Star of the East"; e os americanos: Benny Leonard, [...], Abe Atell, "Battling Levinsky, Barney Ross, Maxie Rosem-bloom, Al Singer, Max Baer; todos saltitando impacientes na areia úmida, trocando socos para esquentar; e o Homem-Montanha [...] ao lado do Vingador, do Calunga e do Zorro; [...] Estavam ali os americanos, os ingleses, os franceses, os russos. E a FEB. E os fiéis "pelos-duros", os nativos de Capão da Canoa. E Deus. (SCLIAR, 1981, p. 78-79)

O discurso motivador feito pelo rei Joel aos companheiros tinha como máxima exaltar as qualidades e enumerar os nomes dos poderosos aliados a fim de que sua turma acreditasse numa vitória em equipe na nova batalha contra os alemães. Ao lado de Joel, estavam tanto figuras estampadas nas revistas e gibis que lia na infância quanto as nações aliadas contra a Alemanha na Segunda Guerra Mundial, além de personagens importantes que fariam o reconhecimento do território com maior facilidade que os estrangeiros: os nativos de Capão da Canoa. Como resultado deste combate, baixas, descritas na narrativa, aconteceram, evidenciando mais uma das variantes propostas por Jameson: as atrocidades. Esta variável presente nos textos que narram a guerra representada caracteriza-se por cenas terríveis e cruéis advindas de eventos limítrofes como o enfrentamento homem a homem nos campos de batalha:

De repente, o Capitão teve uma ideia..chamou Beto e Dudi, pegaram metralhadoras e correram para o mar flanqueando o inimigo. [...] a um brado seu os companheiros correram para a praia, as armas vomitando fogo. Os nazis caíam como moscas; apanhados na armadilha eram varados pelas balas, soqueados pelas soqueiras-punhais, esmagados a coronhaços, furados pelas baionetas, queimados pelos lança-chamas, destroçados pelas granadas, cortados pelos canivetes, iluminados pelos foguetes luminosos e rebentados a pontapés. Tripas juncavam a areia, dentes voavam pelo ar.

[...] o mar ficou juncado de pernas e braços. (SCLIAR, 1981, p. 81-82)

O detalhamento de cada uma das etapas e as diferentes estratégias de guerra empregadas pelo líder Joel conferem verossimilhança à narrativa, bem como as cenas bárbaras mencionadas pelo narrador no combate e posterior vitória sobre os inimigos. Há outras batalhas descritas ao longo da narrativa e com elas mais atrocidades originadas dos confrontos. A primeira mencionada no romance aborda o ataque nazista na Festa do Divino em pleno Bom Fim:

Todos os anos, no inverno, a igreja do Divino cobria-se de luzes coloridas [...] 
No largo, diante da igreja, uma alegre multidão percorria as tendas. Havia rifas e sorteios, carrossel e uma roda-gigante.

Foi nessa que os nazistas concentraram todo o seu ódio.

Uma noite, [...] ouviram-se duas explosões. A roda-gigante parou; toda sua enorme estrutura de aço estremeceu; subitamente liberou-se dos mancais e avançou pelo parque, esmagando tômbolas e tendas, soldados e empregadas, [...]

O povo aplaudiu Joel e seus valentes; e, removidos os cadáveres e escombros, o Parque voltou à atividade [...] (SCLIAR, 1981, p. 25-26)

A normalidade daquela cerimônia tradicional só foi restabelecida pela astúcia do menino Miguel, o Manco - aliado de Joel -, que através de contas e parábolas, calculou a trajetória do brinquedo e garantiu que menos estragos fossem feitos depois do ataque surpresa em pleno momento festivo do Bom Fim. As mortes por esmagamento foram as baixas causadas por aquela ofensiva nazista e poderiam ter sido maiores, se não houvesse o rápido trabalho em equipe do exército daquele que carregava a "marca de Caim" (SCLIAR, 1981, p. 20) em sua testa - Joel.

Outro embate contra os nazistas aconteceu no campinho onde jogavam futebol e, desta vez, baixas do lado de Joel foram inevitáveis:

Enfrentaram os alemães no terreno baldio ao lado da garagem, onde eles estavam entrincheirados. As metralhadoras matraqueavam sem cessar. Caíram mortos Dudi, Jean e Beto. Bons companheiros! Vendo-os tombar, o coração de Joel encheu-se de ódio: "Para a frente, turma" [...] Levou um balaço no ombro, mas continuou avançando. Seguiam-no os fiéis companheiros serrando, cortando, puxando, fincando, esburacando, apedrejando, rachando e sangrando os alemães.

[...] Pedaços de nazis voavam para todo lado!

Não sobrou um só. Centenas de cadáveres amontoavam-se no campinho. (SCLIAR, 1981, p. 54-55)

As atrocidades resultantes dessa batalha sugerem o desejo de extermínio do inimigo em prol do triunfo em tempos de guerra. As mortes dos companheiros de Joel serviram para aumentar a sede de vingança contra os nazistas, dizimados um a um, restando apenas corpos empilhados naquele campo de batalha situado em uma das ruas do Bom Fim.

Com o fim da guerra, o sossego e a paz parecem reinar soberanos no país de Joel. Entretanto, a visão do seu pior inimigo em pleno Bom Fim faz com que o Capitão fique sem atitude por alguns momentos e chega, até mesmo, a adoecer:

Uma tarde Joel vai caminhando pela Avenida Oswaldo Aranha quando o vê - Hitler. Está sentado num bonde J. Abott, junto à janela. Mais velho, com bigode maior - mas é Hitler; indiscutivelmente é Hitler.

Lentamente ele volta a cabeça e olha para Joel. Durante um minuto encaram-se. [...] Joel chega em casa pálido e tremendo; vomita. (SCLIAR, 1981, p. 97)

O susto do guerreiro judeu é tamanho, que, após esse encontro terrível e inimaginável, emagrece, fica em casa de repouso, tem insônia e sente-se sufocado com um segredo impossível de ser revelado. Após seu restabelecimento, há ainda um segundo encontro com Hitler e, desta vez, Joel - ainda convalescente - segue-o para dar fim àquele mal que amea- 
çava novamente a tranquilidade de sua nação. Ao descobrir o local de encontro secreto dos nazistas com seu líder maior, Joel esconde-se e ataca:

[Joel] escala um muro e espia; [...] Hitler reunido com seus asseclas. Na parede, a crus gamada. Hitler fala, gesticula. Todos levantam o braço: Heil!

Um guarda aproxima-se do local onde Joel está. Do alto do muro, ele salta sobre o nazi, domina-o, tira-lhe o revólver, prostra-o com uma coronhada. Pé ante pé aproximase da entrada. [...] Põe a porta abaixo com um pontapé, entra correndo e disparando. Gritos. Uma explosão. Uma fumaça acre enche a casa.. (SCLIAR, 1981, p. 98-99)

Apesar de ter o ombro ensanguentado, o Capitão Joel é o único a sair daquele ataque surpresa com vida. Desta vez, o inimigo estava liquidado. A tecnologia empregada neste combate vem das mãos inimigas - o revólver retirado do guarda nazista - e com ela Joel adentra o esconderijo dos aliados de Hitler e dispara contra todos, massacrando-os.

Ao refletir sobre as perdas afetivas e seu estado atual, Joel - agora um adulto - percebe a degradação daqueles meninos guerreiros que enfrentaram diversas vezes o exército nazista. Pensa na gata Lisl, na égua "Malke Tube", no cão "Melâmpio", nos seus avós, na sua mãe e no seu irmão, no final trágico de seu pai (talvez ignorado por Joel), os amigos e aliados, e não vislumbra redenção, apenas morte e fracasso daqueles que não estão mais a seu lado. Neste ponto, a variante proposta por Jameson acerca da experiência coletiva da guerra faz contabilizar as perdas e ganhos provenientes das disputas dos meninos judeus para defender o Bom Fim. O fracasso do grupo como um todo é interpretado por Gilda Szklo, ao perceber que, "da fantasia à realidade, há uma perda, no caso, a da dimensão aurática. Do imaginário ao documento há, diríamos, um apagamento do fantástico e um esvaziamento da tradição, que acompanham a declinante trajetória de seus protagonistas" (SZKLO, 1990, p. 73).

Sendo assim, a contabilidade negativa ao final do romance nesta transição do fantástico ao real, pode ser pensada no que tange ao sentimento do povo judeu que, "com sua segurança ameaçada, se deixa levar para a fantasia, para o mundo do faz-de-conta. Sonhando com triunfos imaginários, ele se consola, seu mal-estar não parece tão profundo" (SZKLO, 1990, p. 61). No entanto, após o percurso realizado, a dura e brutal realidade mostra-se ainda mais amarga aos olhos daqueles que saíram vitoriosos, por inúmeras vezes, no universo mágico, já que não há realização no mundo real. O peso de uma tradição repleta de sofrimentos e marcada pela perseguição nazista é o duro e amargo fardo dos judeus.

Com o final da guerra e consequente crescimento das crianças do Bom Fim, responsabilidade e maturidade começam a fazer parte da rotina dos jovens e, principalmente, preocupam o ex-líder do grupo:

Joel terminou o ginásio no Júlio de Castilhos; sua voz ficou grossa e ele tinha certos sonhos. [...]

Lá fora, na escuridão, os espíritos bailavam: Nathan tocando violino; Macumba com a marmita na mão; "Malke Tube"; Marcos, de braços e pernas finos e secos como patas de barata. "Tenho de ficar rico" - pensou um dia Joel. "Meu Deus, tenho que ficar rico. A pobreza mata." (SCLIAR, 1981, p. 100-101)

Ao relembrar aqueles que se foram e encontrar um ponto em comum entre todos eles - a condição desfavorecida -, Joel chega à conclusão de que precisava enriquecer, pois 
ser pobre era como estar morto. Berta Waldman reflete sobre essa questão: "uma vez crescidas, o inimigo das crianças não é mais o nazista, mas o mesmo que assola a classe média brasileira: a pobreza" (WALDMAN, 2004, p. 51). Desta maneira, o pensamento de Joel na fase adulta tinha outro adversário a ser combatido, não mais os alemães, mas a situação financeira precária em que se encontrava e que o igualava aos falecidos que faziam parte do seu convívio.

O primeiro emprego de Joel é como vendedor de joias com Ely, pois ambicionava entrar na faculdade, mas antes precisava, e muito, de dinheiro. Sem uma relação afetiva estável, carente de amigos leais, morando de aluguel no centro de Porto Alegre, com pouco dinheiro e dirigindo um Karmann-Ghia, Joel aparece no final do romance sem um norte em sua vida: "Joel caminhou até seu automóvel, [...] deu a partida e arrancou lentamente, sem saber para onde ir" (SCLIAR, 1981, p. 117). A incerteza do protagonista em decidir seu destino, após retornar de uma viagem a Torres, remete de imediato à eterna errância do povo judeu destinado a migrar pelo mundo em busca de uma nova Terra Santa, locus amoenus promissor de emprego e enriquecimento.

Deste modo, a experiência existencial pela qual passou a personagem é o microcosmos de toda uma geração de imigrantes que chega ao Brasil e sofre com o desenraizamento, além de enfrentar as dificuldades de integração local, sendo vítima de preconceito, ocupando sempre a posição de "estranho, sempre marginalizado e perseguido" (SZKLO, 1990, p. 62). Joel é, portanto, "o herói caricato de um mundo consolidado na violência" (SZKLO, 1990, p. 73) que se defende das brutalidades do mundo real com as asas mágicas emprestadas do irmão Nathan, criando um universo fantástico-maravilhoso onde a história e as lendas judaicas ganham vida.

\section{Considerações finais}

A guerra representada no primeiro romance de Scliar possui algumas das variantes enumeradas por Fredric Jameson. Foi possível identificar seis delas: experiência existencial da guerra; experiência coletiva da guerra; líderes, oficiais e o exército; tecnologia; atrocidades; e o ataque à pátria.

Os conflitos oriundos da fértil imaginação do menino judeu Joel possuem todas as características e descrições detalhadas de ataques bélicos reais, por isso é possível analisar a guerra representada no romance, bem como as variantes propostas por Jameson.

As tecnologias empregadas pelos meninos do Bom Fim eram, na maioria das vezes, inferiores ao poderio bélico do inimigo, com exceção do líder Joel que tinha em seu poder granadas e metralhadora. Contudo, mesmo deficitários em suas armas, a vitória era sempre do Capitão e seu grupo.

Os ataques alemães protagonizados em pleno território judaico são descritos com riqueza de detalhes e sutilezas que se apresentam ao leitor como conflitos de guerra, mostrando até mesmo as atrocidades oriundas daqueles combates.

Ao refletir sobre a experiência coletiva da guerra, bem como acerca da experiência existencial do protagonista Joel, entreveem-se resultados negativos em ambas: seja por ter a guerra vitimado muitos de seus amigos e parentes, seja por deixá-lo solitário e nostálgico dos tempos felizes perto dos familiares. A precária condição em que se encontra o líder Joel 
na fase adulta é resultado de uma vida de lutas e limitações que se assemelha à vida de todo povo judeu.

\section{REFERÊNCIAS}

JAMESON, Fredric. War and Representation. In: PMLA: Vol.124, Number 5, October 2009, p. 1532-1546.

SCLIAR, Moacyr. A guerra no Bom Fim. Porto Alegre: L\&PM, 1981.

SZKLO, Gilda S. O Bom Fim do Shtetl: Moacyr Scliar. São Paulo: Perspectiva, 1990.

WALDMAN, Berta. A guerra no Bom Fim: uma forma seminal? In: ZILBERMAN, Regina; BERND, Zilá. (Org.) $O$ viajante transcultural: leituras da obra de Moacyr Scliar. Porto Alegre: EDIPUCRS, 2004.

Recebido em: 17/05/2015

Aceito em: 21/06/2015

${ }^{\text {i }}$ Doutora em Letras pela UFRGS e professora do Instituto Federal de Educação, Ciência e Tecnologia do Rio Grande do Sul - IFRS Campus Canoas. Organizadora do livro Crônicas de viagem do século XXI: olhares sobre as cidades (2014). E-mail: sheilastaudt@ hotmail.com. 